\title{
Prevalence and correlates of suicidal ideation in Korean firefighters: a nationwide study
}

\author{
Heyeon Park', Johanna Inhyang Kim², Beomjun Min', Sohee $\mathrm{Oh}^{3}$ and Jeong-Hyun Kim ${ }^{1,4,5^{*}}$
}

\begin{abstract}
Background: It is generally known that firefighters are at increased risk of suicide. However, the prevalence and correlates of suicidal ideation in firefighters have not been thoroughly described to date. The aim of this study was to measure the 1-year prevalence of suicidal ideation in firefighters and to investigate the correlates of past-year suicidal ideation among the demographic, occupational and clinical characteristics.

Method: A web-based survey was conducted using a self-reported questionnaire. A total of 45,698 Korean firefighters were included for analysis. The prevalence of suicidal ideation in the past year was calculated and its correlates were elucidated using a multivariable logistic regression analysis.

Results: The 1-year prevalence of suicidal ideation was $10.66 \%$ in Korean firefighters. Recent traumatic experience, high levels of occupational stress from physical work environment and emotional labor, as well as current duty of officer were significant correlates of suicidal ideation in the previous year, even after controlling for the effects of PTSD and depressive symptoms. With respect to demographic factors, female gender and marital status of divorced/separated/widowed were identified to be associated with suicidal ideation in the previous year among firefighters.

Conclusions: The 1-year prevalence of suicidal ideation was high in Korean firefighters and was associated with various occupational factors as well as psychiatric symptoms. Early detection and management of these risk factors could reduce the risk of suicidal ideation in firefighters.
\end{abstract}

Keywords: Firefighters, Suicidal ideation, Prevalence, Occupational stress, Emotional labor

\section{Background}

Suicide and associated behaviors are major public mental health issues around the world. Suicide is one of the leading causes of death worldwide for adults [1]. South Korea, in particular, is a country with a markedly high rate of suicide for the past several years. According to the World Health Organization, the suicide rate in South Korea was 26.9 per 100,000 persons, ranking 4th highest in the world $[2,3]$. One way to prevent suicide is to

\footnotetext{
*Correspondence: retrial3@hanmail.net

'Department of Public Health Medical Services, Seoul National University Bundang Hospital, 82 Gumi-ro 173 Beon-gil, Bundang-gu, Seongnam-si, Gyeonggi-do 13620, South Korea

${ }^{4}$ Mental Health and Behavioral Medicine Services for Clinical Departments, Seoul National University Bundang Hospital, 82 Gumi-ro 173 Beon-gil,

Bundang-gu, Seongnam-si, Gyeonggi-do 13620, South Korea

Full list of author information is available at the end of the article
}

identify the risk factors associated with increased suicidal behaviors, including ideation, plan, and attempt, since they have been found to be predictors for completed suicide [4-6]. Especially, suicidal ideation is strongly associated with a variety of psychological difficulties and subsequent suicide attempts $[7,8]$. Therefore, factual survey and investigation of suicidal ideation in various populations are needed to prevent suicide.

One occupation group that particularly deserves such attention is firefighters because they frequently experience traumatic events that may increase suicidal behaviors $[9,10]$. It was recently reported that the number of firefighters who died from suicide was greater than the number who died in the line of duty in United States [11]. In South Korea, there were also more suicides than on-the-work deaths in firefighters during the last decade,

(c) The Author(s). 2019 Open Access This article is distributed under the terms of the Creative Commons Attribution 4.0 International License (http://creativecommons.org/licenses/by/4.0/), which permits unrestricted use, distribution, and 
according to an informal report from the National Fire Agency. However, the rate of suicide and suicidal behaviors among firefighters are markedly less investigated compared with other groups of first responders, such as police officers [12]. One previous study has tried to determine the career prevalence of suicidal behaviors, including suicidal ideation, plans, and attempts by analyzing data obtained from a sample of 1027 current and retired firefighters in the United States (US). This study reported very high rate of suicidal ideation, plan, and attempt in US firefighters compared with the general population [13]. However, this study included an integrated population of firefighters, ranging from volunteers to retired firefighters in the US; therefore, it may be necessary to conduct research on firefighters who are currently working as professional in other countries. Moreover, this previous study employed a retrospective survey on whole career of participants, so it is highly possible that the participants' perspective on their suicidal behaviors may have been skewed. To investigate suicidal ideation related to firefighters' work and its various correlates, research on data of recent suicidal ideation is needed.

Psychiatric symptoms, such as depression, posttraumatic stress disorder (PTSD) symptoms [14, 15], and sleep disturbances [16], were revealed to be major risk factors associated with suicidal behaviors in firefighters. In addition, lower rank, fewer years of firefighter service, active duty military status, history of professionally responding to suicidal attempt or death cases, and membership in an all-volunteer department were reported as occupational correlates of suicidal ideation among firefighters [13]. However, it is still uncertain whether and how work-related stress in their occupational environment impacts suicidal ideation in firefighters, despite attempts to identify the predictors for suicidal behaviors in this population. Previous epidemiological studies showed a potential association between occupational stress and suicidal ideation in emergency workers. Specifically, jobrelated emotional exhaustion and bullying at work were associated with suicidal ideation in Norwegian ambulance personnel [17]. Also, having been harassed at work was associated with suicidal ideation among physicians in academic medicine [18]. Considering these findings, occupational stress might be associated with suicidal ideation in such population.

Several occupational stressors unique to firefighters are necessary to be investigated. First, traumatic experience while on duty might be the highest risk factor related to suicidal ideation. Traumatic experiences in firefighters have been widely acknowledged as a major risk factor for various mental disorders. The severity of PTSD symptoms and traumatic experience were positively related with the risk of lifetime suicidal ideation and attempts [14]. However, it remains unknown whether and how a recent exposure to traumatic event impacts suicidal ideation in firefighters. Second, occupational stress from risky or hostile workplace environment might also be a risk factor for suicidal ideation in firefighters $[19,20]$. In particular, firefighters routinely suffer from harsh working condition, exposed to physical danger while on duty, outdoor work regardless of weather, handling of heavy equipment, and irregular work hours. Investigations are needed to determine whether occupational stress related to the characteristics of the physical work condition is one of the correlates of suicidal ideation in firefighters. In addition, emotional labor might also be one of the occupational stressors. Emotional labor is the process of controlling feelings in compliance with the organizational demands and occupational duties [21-23]. Firefighters have to hide their own emotions when they face sickness, death, suicide, and violent accidents. Moreover, it has been found that firefighters usually suffer from emotional labor similar to those in customer-service industry due to the aggressive and/or picky nature of civil petitioners in Korea [24]. Considering the previous findings that emotional labor has a negative impact on mental health among workers [25-29], it is needed to investigate whether emotional labor is associated with suicidal ideation in firefighters.

In this study, we conducted a nationwide survey on past-year suicidal ideation and its correlates among 45, 698 firefighters in South Korea. The purpose of this study was twofold: 1) to determine the 1-year prevalence of suicidal ideation in firefighters and 2) to investigate whether and how demographic characteristics (age, sex, marital status, and religion), occupational factors (current duty, traumatic experience in the previous year, stress from physical work condition, and emotional damage from emotional labor), and clinical symptoms (PTSD and depression) are correlated with past-year suicidal ideation in this population.

\section{Methods}

\section{Participants}

This nationwide cross-sectional study was conducted between February 2018 and March 2018 via a self-reported online survey among Korean firefighters. A total of 45, 719 firefighters in South Korea participated in the survey and completed the self-reported questionnaire, including their suicidal ideation in the past year, as well as demographic characteristics and occupational factors, such as traumatic experience in the past year, occupational stress, emotional labor, and clinical factors, including PTSD and depression symptoms. Among the total, 21 were excluded from the final analyses due to coding error during the survey. Thus, the final analysis included 
a total of 45,698 firefighters. Survey respondents were apprised of the anonymous and voluntary nature of the self-reported online survey.

\section{Measures}

\section{Demographic and occupational characteristics}

The demographic and occupational characteristics were obtained using a self-reported questionnaire. Demographic characteristics included age, sex (male or female), marital status (married, never married, or divorced/separated/widowed), and religion (yes or no). Occupational characteristics included length of work (years) and current duty. The roles of firefighters include fire suppression, special investigation of the cause of fire, paramedics providing emergency medical care, rescuing people who are trapped or in medical emergencies, training other firefighters, and others [30]. For analysis, the roles were categorized into the following: fire suppression, emergency medical services (EMS: includes paramedics and rescue), and officers (including administrators, special investigators, trainers of firefighters, and communicational and informational system operators).

\section{Suicidal ideation in the past year}

Suicidal ideation in the previous year was assessed using an item of the Suicidal Behavior Questionnaire-Revised (SBQ-R) [31]. The SBQ-R is a brief self-reported questionnaire to inquire about the various aspects of suicidal behaviors. Item 1 explores whether the respondents have ever thought about or attempted suicide in his/her lifetime; item 2 evaluates how often the respondents have thought about suicide over the past 12 months; item 3 assesses the threats of suicide attempts; and item 4 explores the self-reported likelihood of suicidal behaviors in the future. In this study, we used item 2 to assess past-year suicidal ideation in participants. Item 2 reads: "How often have you thought about killing yourself in the past year?" Participants responded to this item on a 5-point Likert scale: 1-never; 2-rarely (1 time); 3sometimes (2 times); 4-often (3-4 times), and 5-very often ( 5 or more times). A score of greater than 2 on item 2 was indicated as having suicidal ideation more than once in the past year. According to the validation study for the SBQ-R, item 2 had the largest effect size followed by item 1 for differentiating between suicidalrisk and non-suicidal participants in both clinical and nonclinical adult sample population [31]. The correlation coefficient between SBQ-R item 2 and PHQ-9 item 9, which inquires about the frequency of suicidal thought over the last 2 weeks, was $r=0.499(p<0.001)$. Additionally, the correlation coefficient between SBQ-R item 2 and the total score of PHQ-9 was $r=0.479$ $(p<0.001)$.

\section{The presence of recent exposure to traumatic events}

Exposure to traumatic events during the previous year was identified by using the self-reported measure - developed by Beaton et al. - which assessed duty-related incident stressors [32]. Twenty-two items were selected among the original 33 incident stressors based on the previous result of rating the stressfulness of the 33 stressors [32]. We excluded two stressors related to gunshots due to the generally low rate of gunshot incidents due to strict gun control laws in South Korea. In South Korea, only government-authorized personnel can own or carry guns. Gun culture is notably absent outside of the military, and gun ownership and death rank among the lowest in the world [33]. 'Witness duty-related death of co-worker' and 'co-worker firefighter fire fatality (not witnessed)' were changed to 'witness duty-related death or suicide of co-worker' and 'co-worker death or suicide (not witnessed), respectively. Finally, three additional stressors, 'remove the body of a suicide victim', 'remove a severely decayed corpse', and 'involved in a safety accident that received public spotlight', which were reported to be frequently encountered and associated with high level of stress in Korean firefighters, were added (Additional file 1: Table S1). Participants were asked whether they were exposed to each stressor in the previous year. More than one exposure to traumatic events in the previous year was regarded as having recent exposure to traumatic events.

\section{Occupational stress from physical work environment}

Occupational stress from physical work environment was measured using the subscale, 'Difficult Physical Environment' of the Korean Occupational Stress Scale (KOSS) [34], which was developed and validated using a nationwide epidemiological study to estimate job stress in Korean employees. The KOSS was based on the most commonly used job stress questionnaires, such as the Job Content Questionnaire [35], National Institute of Occupational Safety and Health job stress questionnaire [36], and Occupational Stress Index [37]. The KOSS has eight subscales (Difficult Physical Environment, High Job Demand, Insufficient Job control, Inadequate Social Support, Job Insecurity, Organizational Injustice, Lack of Reward, and Discomfort in Occupational Climate). The 'Difficult Physical Environment' of the KOSS has three items, each of which was rated on a 4-point Likert scale (1: strongly disagree to 4: strongly agree); higher scores represented higher levels of occupational stress from physical environment. Additional file 2: Table S2 illustrates each item on the "Difficult Physical Environment" subscale of the KOSS. The internal consistency of "Difficult Physical Environment" of KOSS based on the presented sample was $\alpha=0.464$. 


\section{Emotional labor}

Emotional labor was assessed by the Korean Emotional Labor Scale (KELS) [38]. The KELS was developed and validated in a nationwide study to measure emotional labor in Korean employees by the Korean Occupational Safety \& Health Agency. The KELS was based on the previous studies [21-23, 39], the most commonly used emotional labor scales [6, 40, 41], and a focused group interview. The KELS has five subscales which are Effort to Control Emotion, Organizational Monitoring System, Demands of Emotional Labor, Emotional Damage, and Organizational Support System. Each item of the KELS was rated on a 4-point Likert scale, from 1 (not at all) to 4 (very much), and higher scores indicated higher levels of stress from emotional labor. The current study included only the subscale, "Emotional Damage," which measures the severity of emotional hurt due to emotional labor. We regarded the subscale score as proxies for emotional labor in firefighters, because "Emotional Damage" is a factor that explained the most variance of the KELS in the results of a factor analysis in a previous study that developed the scale [38]. Additional file 2: Table S2 shows each item in the "Emotional Damage" subscale of the KELS. The internal consistency of "Emotional Damage" of KELS based on the presented sample was $\alpha=0.947$.

\section{PTSD symptoms}

PTSD symptoms were assessed with the Korean version of PTSD Checklist-for the fifth edition of the Diagnostic and Statistical Manual of Mental Disorders (PCL-5) [42]. The PCL-5 is a 20-item self-reported measure evaluating the degree to which an individual has been bothered in the past month by DSM-5 (Diagnostic and Statistical Manual of Mental Disorders, 5th edition) PTSD symptoms [43]: intrusions, avoidance, negative alteration in cognition and mood, and alterations in arousal and reactivity. We instructed the participants to choose and describe the most traumatic event from a list of traumatic events and fill out the PCL-5 with this event in mind. Each item was measured on a 5-point Likert scale (0: not at all to 4: extremely). Higher scores represented higher severity of PTSD symptoms. Items 1-5 correlated with symptoms within Cluster B (intrusions); items 6-7 with Cluster C (avoidance); items 8-14 with Cluster D (negative alteration in cognition and mood); and items 15-20 with Cluster $\mathrm{E}$ (alterations in arousal and reactivity). The internal consistency of $\mathrm{PCL}=5$ based on the presented sample was $\alpha=0.961$. Participants were considered to be experiencing the symptom when recording a score of 2 or higher (moderately to extremely) in each item. According to an algorithm-derived PTSD diagnosis method, we defined probable PTSD as having the required number of symptoms in each cluster of the
DSM-5 criteria: $1 \mathrm{~B}$ item, $1 \mathrm{C}$ item, $2 \mathrm{D}$ items, and $2 \mathrm{E}$ items.

\section{Depression symptoms}

Depression symptoms were assessed using the Korean version of Patient Health Quetionnaire-9 (PHQ-9) [44, 45]. Respondents rated 9 items, based on the DSM-IV criteria of major depressive disorder, measured on a 4point Likert scale (0: not at all to 3: nearly every day) based on their experiences during the past 2 weeks. The PHQ-9 total score ranged from 0 to 27; higher scores indicated a greater severity of depressive symptoms. The internal consistency of PHQ-9 based on the presented sample was $\alpha=0.905$. The total score of over 15 was defined as probable depression [45].

\section{Statistical analysis}

Descriptive statistics were used to analyze the demographic, occupational, and clinical characteristics of participants, as well as to calculate the 1-year prevalence of suicidal ideation. Chi-square test and $t$-test were used to examine whether there were differences in the demographic, occupational, and clinical characteristics between firefighters with and without suicidal ideation in the past year. Multivariable logistic regression analysis was used to examine the demographic (age, sex, marital status, and religion), occupational (current duty, recent traumatic experience, occupational stress, and emotional labor), and clinical (probable PTSD and depression) characteristics as correlates of suicidal ideation in the previous year. The dependent variable was suicidal ideation in the past year. In the logistic regression analysis, 143 participants with missing data were excluded; thus, a total of 45,555 participants were included in the analysis. The results were shown as the odds ratios (ORs) and $95 \%$ confidence intervals (CIs). The data were analyzed using IBM SPSS Statistics ver. 22.0 software (IBM Corp., Chicago, IL, USA). A two-tailed $p$-value $<0.001$ was considered statistically significant.

\section{Results}

The mean age of all 45,698 participants was 42.51 years (standard deviation, $\mathrm{SD}=9.10$ ), and $92.6 \%$ were males. The average length of work was 13.4 years $(S D=9.43)$. As a current duty, fire suppression, EMS, and officers were $41.57,32.10$, and $26.33 \%$, respectively. In the past year, $62.52 \%$ of participants experienced traumatic events. A total of 4871 (10.66\%) firefighters had suicidal ideation more than once in the past year. With respect to clinical characteristics, a total of 1202 firefighters (2.63\%) were identified as having probable PTSD using PCL-5, and 561 firefighters (1.23\%) were identified as having probable depression using PHQ-9. 
The results in Table 1 show that there were differences in the demographic, occupational, and clinical characteristics between firefighters with and without suicidal ideation in the past year. The association of suicidal ideation in the previous year with demographic, occupational, and clinical characteristics was investigated by using a multivariable logistic regression model. The results are shown in Table 2. Suicidal ideation in the past year was associated with female gender $(\mathrm{OR}=1.484,95 \% \mathrm{CI}=$ $1.328-1.657)$ and with relationship status as divorced/ separated/widowed $(\mathrm{OR}=1.724,95 \% \mathrm{CI}=1.432-2.076)$. As current duty, officers were more likely to be related to suicidal ideation in the past year $(\mathrm{OR}=1.488,95 \%$ $\mathrm{CI}=1.366-1.622)$, compared with fire suppression. The presence of recent trauma $(\mathrm{OR}=1.847,95 \% \mathrm{CI}=1.709$ 1.997), higher occupational stress $(\mathrm{OR}=1.191,95 \% \mathrm{CI}=$ 1.164-1.219), higher emotional labor $(\mathrm{OR}=1.095,95 \%$
$\mathrm{CI}=1.087-1.103)$, probable $\mathrm{PTSD}(\mathrm{OR}=4.008,95 \% \mathrm{CI}=$ 3.499-4.591), and probable depression ( $\mathrm{OR}=8.916,95 \%$ $\mathrm{CI}=7.201-11.039)$ were also significantly associated with suicidal ideation in the past year.

\section{Discussion}

This is, to the best of our knowledge, the first nationwide epidemiological study investigating the 1-year prevalence of suicidal ideation in firefighters. In this study, we found that $10.66 \%$ of Korean firefighters reported having suicidal ideation in the past year, which is higher than in the Korean general population. A nationwide study conducted by the Korean Epidemiologic Catchment Area Study Replication (KECA-R) in 2016 showed that the 1-year prevalence of suicidal ideation in the Korean general population was $2.9 \%$, using the Korean version of the Composite International Diagnostic

Table 1 The demographic, occupational, and clinical characteristics by suicidal ideation in the past year $(N=45,698)$

\begin{tabular}{|c|c|c|c|}
\hline & \multicolumn{2}{|l|}{$\mathrm{N}(\%)$ of $\mathrm{M} \pm \mathrm{SD}$} & \multirow{2}{*}{$\begin{array}{l}\text { T or Chi- } \\
\text { square }\end{array}$} \\
\hline & Suicidal ideation & No suicidal ideation & \\
\hline Age & $43.01 \pm 8.52$ & $42.45 \pm 9.16$ & $t=4.31^{*}$ \\
\hline \multicolumn{4}{|l|}{ Sex } \\
\hline Male & $4344(89.18)$ & $37,982(93.03)$ & \multirow[t]{2}{*}{$x^{2}=91.42^{*}$} \\
\hline Female & $527(10.82)$ & $2845(6.97)$ & \\
\hline \multicolumn{4}{|l|}{ Marital status $(N=45,606)$} \\
\hline Married & $3753(77.22)$ & $30,813(75.62)$ & \multirow[t]{3}{*}{$x^{2}=98.86^{*}$} \\
\hline Never married & $929(19.12)$ & $9195(22.57)$ & \\
\hline Divorced/separated/widowed & $178(3.66)$ & $738(1.81)$ & \\
\hline \multicolumn{4}{|l|}{ Religion $(N=45,555)$} \\
\hline No & $3101(63.96)$ & $26,532(65.18)$ & \multirow[t]{2}{*}{$x^{2}=2.81$} \\
\hline Yes & $1747(36.04)$ & $14,175(34.82)$ & \\
\hline Work length (year) & $13.93 \pm 8.97$ & $13.30 \pm 9.48$ & $t=4.62^{*}$ \\
\hline \multicolumn{4}{|l|}{ Current duty } \\
\hline Fire suppression & $1968(40.40)$ & $17,028(41.71)$ & \multirow[t]{3}{*}{$x^{2}=28.68^{*}$} \\
\hline EMS & $1468(30.14)$ & $13,203(32.34)$ & \\
\hline Officer & $1435(29.46)$ & $10,596(25.95)$ & \\
\hline \multicolumn{4}{|l|}{ Recent trauma } \\
\hline No & $1094(22.46)$ & $16.34(39.27)$ & \multirow[t]{2}{*}{$x^{2}=525.01^{*}$} \\
\hline Yes & $3777(77.54)$ & $24,793(60.73)$ & \\
\hline Occupational stress & $7.94 \pm 1.62$ & $7.07 \pm 1.65$ & $t=35.06^{*}$ \\
\hline Emotional labor & $16.11 \pm 4.66$ & $12.58 \pm 5.04$ & $t=49.50^{*}$ \\
\hline \multicolumn{4}{|l|}{ Probable PTSD } \\
\hline No & $4240(87.05)$ & $40,256(98.60)$ & \multirow[t]{2}{*}{$x^{2}=2268.95^{*}$} \\
\hline Yes & $631(12.95)$ & $571(1.40)$ & \\
\hline \multicolumn{4}{|l|}{ Probable Depression } \\
\hline No & $4454(91.44)$ & 40,683 (99.65) & \multirow[t]{2}{*}{$x^{2}=2418.02^{*}$} \\
\hline Yes & $417(8.56)$ & $144(0.35)$ & \\
\hline
\end{tabular}


Table 2 Demographic, occupational, and clinical correlates of suicidal ideation in the past year $(N=45,555)$

\begin{tabular}{|c|c|c|c|c|c|}
\hline & B & SE & OR & $95 \% \mathrm{Cl}$ & $p$ \\
\hline Age & 0.007 & 0.002 & 1.007 & $1.003-1.012$ & 0.002 \\
\hline \multicolumn{6}{|l|}{ Sex } \\
\hline \multicolumn{6}{|l|}{ Male (reference) } \\
\hline Female & 0.394 & 0.056 & 1.484 & $1.328-1.657$ & $<0.001$ \\
\hline \multicolumn{6}{|l|}{ Marital status } \\
\hline \multicolumn{6}{|l|}{ Married (reference) } \\
\hline Never married & 0.000 & 0.049 & 1.000 & $0.909-1.101$ & 0.997 \\
\hline Divorced/separated/widowed & 0.545 & 0.095 & 1.724 & $1.432-2.076$ & $<0.001$ \\
\hline \multicolumn{6}{|l|}{ Religion } \\
\hline \multicolumn{6}{|l|}{ No (reference) } \\
\hline Yes & 0.001 & 0.034 & 0.999 & $0.935-1.068$ & 0.984 \\
\hline \multicolumn{6}{|l|}{ Current duty } \\
\hline \multicolumn{6}{|l|}{ Fire suppression (reference) } \\
\hline EMS & 0.271 & 0.043 & 0.762 & $0.701-0.829$ & $<0.001$ \\
\hline Officer & 0.398 & 0.044 & 1.488 & $1.366-1.622$ & $<0.001$ \\
\hline \multicolumn{6}{|l|}{ Recent traumatic experience } \\
\hline \multicolumn{6}{|l|}{ No (reference) } \\
\hline Yes & 0.614 & 0.040 & 1.847 & $1.709-1.997$ & $<0.001$ \\
\hline Occupational stress & 0.175 & 0.012 & 1.191 & $1.164-1.219$ & $<0.001$ \\
\hline Emotional labor & 0.091 & 0.004 & 1.095 & $1.087-1.103$ & $<0.001$ \\
\hline \multicolumn{6}{|l|}{ Probable PTSD } \\
\hline \multicolumn{6}{|l|}{ No (reference) } \\
\hline Yes & 1.388 & 0.069 & 4.008 & $3.499-4.591$ & $<0.001$ \\
\hline \multicolumn{6}{|l|}{ Probable depression } \\
\hline \multicolumn{6}{|l|}{ No (reference) } \\
\hline Yes & 2.188 & 0.109 & 8.916 & $7.201-11.039$ & $<0.001$ \\
\hline
\end{tabular}

EMS Emergency Medical Services, $B$ regression coefficients, SE Standard error of regression coefficient, OR Odd Ratio, Cl Confidence Interval

Interview [46]. From this, we may suppose that more firefighters experience suicidal ideation during their active duty period than the general population with other occupation, indicating that there might be risk factors unique to the occupation of firefighting.

A previous study reported a career prevalence of suicidal behavior among American firefighters [13]; it reported that the career prevalence of suicidal ideation, plan, and attempt was 46.8, 19.2, and $15.5 \%$, respectively. These figures are much higher compared with our results. This difference might be attributable to several reasons. First, their data was obtained from a relatively small sample (1027 firefighters), while our data was obtained from a relatively large sample size (45,698 firefighters). Second, their study included an integrated population of firefighters, ranging from volunteers to retired firefighters, and showed that volunteers were more likely to report suicidal behaviors than full-timers. However, in our study, only full-time firefighters currently working as professionals were analyzed. Third, their study included firefighters with various races and ethnicities residing in the US, while in our study, only Korean - one race and ethnicity - firefighters were enrolled. Stanley et al. recruited White, Hispanic, Latino, Native American and Alaska Native firefighters; and being $\mathrm{Na}$ tive American or Alaska Native was a key factor associated with increased risk for suicidal behaviors. Finally, we analyzed firefighters' suicidal ideation only in the past year, while Stanley et al. analyzed suicidal ideation in whole career years of firefighters.

In this study, we also investigated the correlates of suicidal ideation in the past year among firefighters. Results showed that PTSD and depressive symptoms were factors most strongly correlated with suicidal ideation in the previous year among demographic, occupational, and clinical characteristics. It is consistent with the previous findings that PTSD and depression were linked to suicidal behaviors [14, 15, 47-50]. Notable finding of this study was that occupational factors were associated with suicidal ideation in firefighters, even after 
controlling for the effect of PTSD and depressive symptoms. First, we found that recent exposure to traumatic event significantly heightened the possibility of developing suicidal ideation in the past year even after adjusting for demographics as well as PTSD and depressive symptoms. In other words, firefighters who experienced a recent traumatic event could be at higher risk for developing suicidal ideation, despite the lack of PTSD or depressive symptoms, immediately following the traumatic event. This finding is consistent with previous studies, showing that the association between traumatic experience and suicidal behaviors held irrespective of a presence of PTSD [51-53]. It is clear that mental disorders, such as PTSD and depression, accounted for a significant portion of the association between suicidal ideation and traumatic experience. However, these findings suggest that the association between suicidal ideation and traumatic experience does not occur only in the presence of psychiatric disorders and that psychiatric disorders might partially mediate the association. Further study is needed to investigate the interactions between traumatic experience and mental disorders in predicting suicidal ideation.

Second, we found a significant association of occupational stress from physical work condition with suicidal ideation in firefighters. There is accumulated evidence that job-related stress is linked to mental health problems in emergency workers as well as the general population [54-57]. In particular, a previous study conducted in four countries - Korea, China, Australia, and Germany - reported that occupational stress, such as job strain, organizational injustice, and effort-rewardimbalance was associated with suicidal ideation [20]. Recently, the association between suicidality and occupational stress, such as discrimination, inadequate pay, disruption of sleep, and concern about serious injury, was reported among firefighters [19]. However, it has not yet been investigated whether occupational stress from a difficult physical environment of workplace is associated with suicidal ideation in workers. Our findings provide some evidence that working in an unsafe environment or suffering from physical danger on duty could heighten the possibility of suicidal ideation in firefighters.

Third, emotional labor as an occupational stress factor had a positive association with suicidal ideation in Korean firefighters. Firefighters should keep their true feelings in hiding when faced with sickness, death, and violent accidents. Moreover, Korean firefighters usually suffer from emotional labor due to unreasonable demands from the aggressive or picky civil petitioners, presenting similar experiences with those in customerservice industry [24]. A recent study showed that emotional labor made firefighters vulnerable to mental problem by modulating the effects of traumatic experiences on PTSD symptoms [29]. Based on previous findings, it is possible that the high demand of emotional labor might be a risk factor for suicidal behaviors alone and by exaggerating the severity of PTSD.

The final occupational factor related to suicidal behaviors was the officer as a present job position among firefighters. Officer positions include administrators, special investigators, and communicational and informational system operators. Though firefighters in officer position may have less chance to be exposed to traumatic experience during work, they may get highly stressed by high administration work load and pressure, less peer support, and lower salary (e.g. lower danger pay) compared with those in fire suppression or EMS.

Among the demographic characteristics, we found that female gender was significantly associated with the risk of suicidal ideation in the past year. This finding is consistent with the previous report that the 1-year prevalence of suicidal ideation was greater in females than men [58]. Compared with other OECD countries, there are major gender gaps in earning, labor market participation, and representation in the government of Korea [59]. This gender discrimination in Korean society could partly explain the higher risk of suicidal ideation in female firefighters. Given that the occupation of firefighting remains heavily male dominated, female firefighters may feel relatively more discomfort in the occupational environment.

This study has several limitations. First, the crosssectional design of the study limits its ability to confirm a causal relationship between suicidal ideation and the demographic, occupational, and clinical factors in firefighters. In the future, longitudinal studies should be conducted to confirm the causal relationship found in this study. The current study collected data from a webbased self-reported questionnaire. Self-report assessment has a wide range of tendencies for the participants to respond inaccurately to questions and the recall bias could have possibly influenced the results. Standardized interviews would provide a more accurate and detailed information regarding the prevalence and correlates of suicidal ideation in the population of firefighters. Furthermore, we used a single-item question to assess pastyear suicidal ideation and thus, we did not measure a broad spectrum of current and previous suicidal thoughts. Further studies are necessary to investigate the suicidal risk and its correlates using a comprehensive assessment of attitudes and behaviors related to suicide in firefighters.

\section{Conclusion}

The 1-year prevalence of suicidal ideation was higher in firefighters than in the general population. Female 
gender, divorced/separated/widowed marital status, current duty of an officer, recent traumatic experience, and high level of occupational stress and emotional labor were significant correlates of suicidal ideation in the past year, even after controlling for the effects of PTSD and depression. These findings suggest that consideration and early detection of these correlates may be important in protecting firefighters from the risk of suicide. Longitudinal studies are needed to determine the causal relationships among these correlates, suicidal ideation, and completed suicide.

\section{Supplementary information}

Supplementary information accompanies this paper at https://doi.org/10. 1186/s12888-019-2388-9.

Additional file 1: Table S1. The list of traumatic events

Additional file 2: Table S2. The list of items on the Korean

Occupational Stress Scale and the Korean Emotional Labor Scale

\section{Abbreviations}

Cl: Confidence interval; DSM-5: Diagnostic and Statistical Manual of Mental Disorders, 5th edition; EMS: Emergency medical services; KECA-R: Korean Epidemiologic Catchment Area Study Replication; KELS: Korean Emotiona Labor Scale; KOSS: Korean Occupational Stress Scale; OR: Odds ratio; PCL5: PTSD Checklist-for the fifth edition of the Diagnostic and Statistical Manual of Mental Disorders; PHQ-9: Patient Health Quetionnaire-9;

PTSD: Posttraumatic stress disorder; SBQ-R: Suicidal Behavior QuestionnaireRevised

\section{Acknowledgements}

The authors would like to thank Ki Young $\mathrm{Na}$, the Vice Director, and Eun Hee Choi of the Department of Public Health Medical Services, Seoul National University Bundang Hospital. We would like to express our gratitude to the following individuals for their dedication to this study: Jae Dong Hwang, the assistant fire chief and health management team manager; Woo Seok Kim, the fire captain; Kyeong Yeol Park, the fire sergeant; and Jeong Pil Sin, the senior firefighter at the Fire Policy Division in Health Management Team from National Fire Agency. We also would like to deeply thank Jina Park and Kyoung Bok Han from the Gyeonggi Disaster and Safety Headquarters.

\section{Authors' contributions}

$J K, H P$, and JIK were involved in the conceptualization and implementation of the study. HP and SO analyzed the data. HP and JK drafted the manuscript, and BM reviewed the drafts of the manuscript. All authors read and approved the final manuscript.

\section{Funding}

This research did not receive any specific grant from funding agencies in the public, commercial, or not-for-profit sectors.

\section{Availability of data and materials}

The datasets used and/or analyzed during the current study are available from the Fire Policy Division in Health Management Team from National Fire Agency of Korea on reasonable request.

\section{Ethics approval and consent to participate}

Ethical approval was obtained from the Institutional Review Board of Seoul National University Bundang Hospital (IRB No: X-1807-483-907). As all data was entered in a completely anonymized manner, consent to participate was not required.

\section{Consent for publication}

As completely anonymized observational data was used (see "Ethics approval and consent to participate"), consent for publication was not required.

\section{Competing interests}

The authors declare that they have no competing interests.

\section{Author details}

${ }^{1}$ Department of Public Health Medical Services, Seoul National University Bundang Hospital, 82 Gumi-ro 173 Beon-gil, Bundang-gu, Seongnam-si, Gyeonggi-do 13620, South Korea. ${ }^{2}$ Department of Psychiatry, Hanyang University Medical Center, 222-1, Wangsimni-ro Seongdong-gu, Seoul, South Korea. ${ }^{3}$ Department of Biostatistics, Seoul Metropolitan Government Seoul National University Boramae Medical Center, Boramae-ro 5-gil, Dongjak-gu, Seoul, South Korea. ${ }^{4}$ Mental Health and Behavioral Medicine Services for Clinical Departments, Seoul National University Bundang Hospital, 82 Gumi-ro 173 Beon-gil, Bundang-gu, Seongnam-si, Gyeonggi-do 13620, South Korea. ${ }^{5}$ Department of Psychiatry, Seoul National University Bundang Hospital, 82 Gumi-ro 173 Beon-gil, Bundang-gu, Seongnam-si, Gyeonggi-do 13620, South Korea.

Received: 20 June 2019 Accepted: 4 December 2019

Published online: 30 December 2019

\section{References}

1. World Health Organization. Suicide in the world: global health estimates. Geneva: World Health Organization; 2019

2. OECD. Making Mental Health Count: The Social and Economic Costs of Neglecting Mental Health Care. Paris: OECD Publishing; 2014.

3. Suicide rate by country population. [http://worldpopulationreview.com/ countries/suicide-rate-by-country/]. Accessed 2 Oct 2019.

4. Carter G, Reith DM, Whyte IM, McPherson M. Repeated self-poisoning: increasing severity of self-harm as a predictor of subsequent suicide. $\mathrm{Br} J$ Psychiatry. 2005;186(3):253-7.

5. Funahashi T, Ibuki Y, Domon Y, Nishimura T, Akehashi D, Sugiura H. A clinical study on suicide among schizophrenics. Psychiatry Clin Neurosci. 2000;54(2):173-9.

6. Mann S. Emotion at work: to what extent are we expressing, suppressing, or faking it? Eur J Work Organ Psychol. 1999;8(3):347-69.

7. Garlow SJ, Rosenberg J, Moore JD, Haas AP, Koestner B, Hendin H, Nemeroff CB. Depression, desperation, and suicidal ideation in college students: results from the American Foundation for Suicide Prevention College screening project at Emory University. Depress Anxiety. 2008;25(6):482-8.

8. Liu KY, Chen EY, Chan CL, Lee DT, Law Y, Conwell Y, Yip PS. Socio-economic and psychological correlates of suicidality among Hong Kong working-age adults: results from a population-based survey. Psychol Med. 2006;36(12): 1759-67.

9. Mazza JJ, Reynolds WM. Exposure to violence in young inner-city adolescents: relationships with suicidal ideation, depression, and PTSD symptomatology. J Abnorm Child Psychol. 1999;27(3):203-13.

10. Carballo JJ, Harkavy-Friedman J, Burke AK, Sher L, Baca-Garcia E, Sullivan GM Grunebaum MF, Parsey RV, Mann JJ, Oquendo MA. Family history of suicidal behavior and early traumatic experiences: additive effect on suicidality and course of bipolar illness? J Affect Disord. 2008;109(1-2):57-63.

11. Fisher N. More firefighters committed suicide in 2017 than died in line of duty. [https://www.forbes.com/sites/nicolefisher/2018/08/23/hauntedheroes-more-firemen-committed-suicide-in-2017-than-died-in-line-of-duty/ \#2e6bbcfe2a24]. Accessed 10 June 2019.

12. Stanley $\mathrm{IH}$, Hom MA, Joiner TE. A systematic review of suicidal thoughts and behaviors among police officers, firefighters, EMTs, and paramedics. Clin Psychol Rev. 2016;44:25-44.

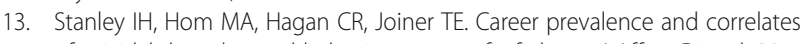
of suicidal thoughts and behaviors among firefighters. J Affect Disord. 2015; 187:163-71

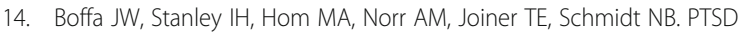
symptoms and suicidal thoughts and behaviors among firefighters. J Psychiatr Res. 2017:84:277-83.

15. Martin CE, Tran JK, Buser SJ. Correlates of suicidality in firefighter/EMS personnel. J Affect Disord. 2017;208:177-83.

16. Vargas de Barros V, Martins LF, Saitz R, Bastos RR, Ronzani TM. Mental health conditions, individual and job characteristics and sleep disturbances among firefighters. J Health Psychol. 2013;18(3):350-8.

17. Sterud T, Hem E, Lau B, Ekeberg $\varnothing$. Suicidal ideation and suicide attempts in a nationwide sample of operational Norwegian ambulance personnel. J Occup Health. 2008;50(5):406-14. 
18. Eneroth M, Sendén MG, Løvseth LT, Schenck-Gustafsson K, Fridner A. A comparison of risk and protective factors related to suicide ideation among residents and specialists in academic medicine. BMC Public Health. 2014; 14(1):271.

19. Stanley IH, Boffa JW, Smith LJ, Tran JK, Schmidt NB, Joiner TE, Vujanovic AA. Occupational stress and suicidality among firefighters: examining the buffering role of distress tolerance. Psychiatry Res. 2018;266:90-6.

20. Loerbroks A, Cho S-I, Dollard MF, Zou J, Fischer JE, Jiang Y, Angerer P, Herr RM, Li J. Associations between work stress and suicidal ideation: individualparticipant data from six cross-sectional studies. J Psychosom Res. 2016;90: 62-9.

21. Brotheridge CM, Grandey AA. Emotional labor and burnout: comparing two perspectives of "people work". J Vocat Behav. 2002;60(1):17-39.

22. Brotheridge CM, Lee RT. Testing a conservation of resources model of the dynamics of emotional labor. J Occup Health Psychol. 2002;7(1):57.

23. Hochschild AR. The Managed Heart. Berkeley and Los Angeles: University of California Press; 1983.

24. Kim SS, Joo YS, Kang TS, Kim MY, Kim SJ, Kim JY, Kim JH, Kim TB, Lee JH, Jung SJ. A survey on human rights of firefighters. Seoul: Seoul National human rights commission of Korea; 2015.

25. Kim I-H, Noh S, Muntaner C. Emotional demands and the risks of depression among homecare workers in the USA. Int Arch Occup Environ Health. 2013; 86(6):635-44.

26. Murcia M, Chastang J-F, Niedhammer I. Psychosocial work factors, major depressive and generalised anxiety disorders: results from the French national SIP study. J Affect Disord. 2013;146(3):319-27.

27. Oh H, Park H, Boo S. Mental health status and its predictors among call center employees: a cross-sectional study. Nurs Health Sci. 2017;19:228-36.

28. Wieclaw J, Agerbo E, Mortensen PB, Burr H, Tuchsen F, Bonde JP. Psychosocial working conditions and the risk of depression and anxiety disorders in the Danish workforce. BMC Public Health. 2008;8(1):280.

29. Park H, Kim Jl, Oh S, Kim J-H. The impact of emotional labor on the severity of PTSD symptoms in firefighters. Compr Psychiatry. 2018;83:53-8.

30. Kim Y-K, Ahn Y-S, Kim K, Yoon J-H, Roh J. Association between job stress and occupational injuries among Korean firefighters: a nationwide crosssectional study. BMJ Open. 2016;6(11):e012002.

31. Osman A, Bagge CL, Gutierrez PM, Konick LC, Kopper BA, Barrios FX. The suicidal behaviors questionnaire-revised (SBQ-R): validation with clinical and nonclinical samples. Assessment. 2001;8(4):443-54.

32. Beaton R, Murphy S, Johnson C, Pike K, Corneil W. Exposure to duty-related incident stressors in urban firefighters and paramedics. J Trauma Stress. 1998;11(4):821-8.

33. National Police Agency of South Korea. Status os permission to possess firearms. In: Department of Life Order - Police Statistics Annual Report. Daejeon Metropolitan City: National Police Agency; 2017.

34. Chang SJ, Koh SB, Kang D, Kim SA, Kang MG, Lee CG, Chung JJ, Cho JJ, Son $\mathrm{M}$, Chae $\mathrm{CH}$. Developing an occupational stress scale for Korean employees. Korean J Occup Environ Med. 2005;17(4):297-317.

35. Karasek R, Brisson C, Kawakami N, Houtman I, Bongers P, Amick B. The job content questionnaire (JCQ): an instrument for internationally comparative assessments of psychosocial job characteristics. J Occup Health Psychol. 1998;3(4):322.

36. Hurrell JJ, McLaney MA. Exposure to job stress: a new psychometric instrument. Scand J Work Environ Health. 1988;14:27-8.

37. Belkic K. The occupational stress index: an approach derived from cognitive ergonomics and brain research for clinical practice. Cambridge: Cambridge International Science Pub.; 2003.

38. Chang SJ, Kang DM, Kang HT, Kim SY, Kim IA, Kim JI, Kim HJ, Kim HR, C. KH, Park SG, et al. Application research for Korean emotional labor scale and Korean workplace violence scale. Seoul: Occupational Safety and Health Research Institute, Korean Occupational Safety \& Health Agency; 2014.

39. Morris JA, Feldman DC. The dimensions, antecedents, and consequences of emotional labor. Acad Manag Rev. 1996;21(4):986-1010.

40. Brotheridge CM, Lee RT. Development and validation of the emotional labour scale. J Occup Organ Psychol. 2003;76(3):365-79.

41. Zapf D, Vogt C, Seifert C, Mertini H, Isic A. Emotion work as a source of stress: the concept and development of an instrument. Eur J Work Org Psychol. 1999;8(3):371-400.

42. Kim JW, Chung HG, Choi JH, So HS, Kang S-H, Kim DS, Moon JY, Kim TY. Psychometric properties of the Korean version of the PTSD Checklist-5 in elderly Korean veterans of the Vietnam war. Anxiety Mood. 2017;13(2):12331.

43. Blevins CA, Weathers FW, Davis MT, Witte TK, Domino JL. The posttraumatic stress disorder checklist for DSM-5 (PCL-5): development and initial psychometric evaluation. J Trauma Stress. 2015;28(6):489-98.

44. Han C, Jo SA, Kwak J-H, Pae C-U, Steffens D, Jo I, Park MH. Validation of the patient health Questionnaire-9 Korean version in the elderly population: the Ansan geriatric study. Compr Psychiatry. 2008;49(2):218-23.

45. Kroenke K, Spitzer RL, Williams JB. The PHQ-9: validity of a brief depression severity measure. J Gen Intern Med. 2001;16(9):606-13.

46. Hong JP, et al. The survey of mental disorder in Korea. Seoul: Ministry of Health and Welfare; 2016.

47. Beck AT, Steer RA, Beck JS, Newman CF. Hopelessness, depression, suicida ideation, and clinical diagnosis of depression. Suicide Life Threat Behav. 1993;23(2):139-45.

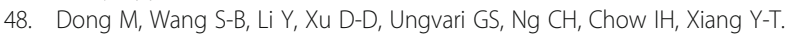
Prevalence of suicidal behaviors in patients with major depressive disorder in China: a comprehensive meta-analysis. J Affect Disord. 2018;225:32-9.

49. Dugas E, Low NC, Rodriguez D, Burrows S, Contreras G, Chaiton M, O'Loughlin J. Early predictors of suicidal ideation in young adults. Can J Psychiatry. 2012;57(7):429-36.

50. Jakupcak M, Cook J, Imel Z, Fontana A, Rosenheck R, McFall M. Posttraumatic stress disorder as a risk factor for suicidal ideation in Iraq and Afghanistan war veterans. J Trauma Stress. 2009;22(4):303-6.

51. Stein DJ, Chiu WT, Hwang I, Kessler RC, Sampson N, Alonso J, Borges G, Bromet E, Bruffaerts R, De Girolamo G. Cross-national analysis of the associations between traumatic events and suicidal behavior: findings from the WHO world mental health surveys. PLoS One. 2010;5(5):e10574.

52. Belik S-L, Cox BJ, Stein MB, Asmundson GJ, Sareen J. Traumatic events and suicidal behavior: results from a national mental health survey. J Nerv Ment Dis. 2007;195(4):342-9.

53. Belik S-L, Stein MB, Asmundson GJ, Sareen J. Relation between traumatic events and suicide attempts in Canadian military personnel. Can J Psychiatry. 2009;54(2):93-104.

54. Cho JJ, Kim JY, Chang SJ, Fiedler N, Koh SB, Crabtree BF, Kang DM, Kim YK, Choi YH. Occupational stress and depression in Korean employees. Int Arch Occup Environ Health. 2008:82(1):47-57.

55. Gallery ME, Whitley TW, Klonis LK, Anzinger RK, Revicki DA. A study of occupational stress and depression among emergency physicians. Ann Emerg Med. 1992;21(1):58-64.

56. Mitani S, Fujita M, Nakata K, Shirakawa T. Impact of post-traumatic stress disorder and job-related stress on burnout: a study of fire service workers. J Emerg Med. 2006;31(1):7-11.

57. Saijo Y, Ueno T, Hashimoto Y. Post-traumatic stress disorder and job stress among firefighters of urban Japan. Prehosp Disaster Med. 2012;27(1):59-63.

58. Borges G, Nock MK, Abad JMH, Hwang I, Sampson NA, Alonso J, Andrade $\mathrm{LH}$, Angermeyer MC, Beautrais A, Bromet E. Twelve month prevalence of and risk factors for suicide attempts in the WHO world mental health surveys. J Clin Psychiatry. 2010;71(12):1617.

59. OECD. The pursuit of gender equality-an uphill Battle. Paris: OECD Publishing; 2017.

\section{Publisher's Note}

Springer Nature remains neutral with regard to jurisdictional claims in published maps and institutional affiliations.

\section{Ready to submit your research? Choose BMC and benefit from:}

- fast, convenient online submission

- thorough peer review by experienced researchers in your field

- rapid publication on acceptance

- support for research data, including large and complex data types

- gold Open Access which fosters wider collaboration and increased citations

- maximum visibility for your research: over $100 \mathrm{M}$ website views per year

At $\mathrm{BMC}$, research is always in progress.

Learn more biomedcentral.com/submissions 